\title{
INCÊNDIOS EM AMBIENTE COM MATERIAIS BRASILEIROS E ESTRANGEIROS: UM ESTUDO COMPARATIVO
}

\author{
George Cajaty Braga ${ }^{1}$ \\ Cristiano Corrêa ${ }^{2}$ \\ Bruno Matos ${ }^{3}$ \\ Jorge Vinícius Fernandes Lima Calvalcanti ${ }^{4}$ \\ Joaquim Pereira Lisboa Neto ${ }^{5}$
}

\section{RESUMO}

O presente artigo apresenta um estudo experimental que visa comparar o desenvolvimento de um incêndio em escala real de dois ambientes mobiliados, um com materiais brasileiros e outro com mobiliário estrangeiro, aferindo temperatura, fluxo de calor, gases emanados e imagens convencionais e térmicas. Cada ambiente estudado continha um sofá e uma televisão, sendo estes fabricados no Brasil para o primeiro experimento e com sofá europeu e televisão estadunidense no segundo. Têm-se em boa parte dos dados apresentados, que o ambiente mobiliado de materiais estrangeiros apresentou um maior retardo para atingir valores máximos de temperatura e fluxo de calor. De maneira geral, os valores máximos para o ambiente com material estrangeiro foram sempre menores, tanto de temperatura quanto de fluxo de calor, quando comparado ao ambiente com mobiliário brasileiro. Verificou-se ainda que as taxas de monóxido de carbono e dióxido de carbono no ambiente com mobiliário brasileiro seriam letais para $50 \%$ da população, após três minutos do início da combustão, se o ocupante permanecesse de pé e atrás do sofá (ponto de coleta gasosa).

Palavras-chave: Segurança contra incêndio, Ensaio em tamanho real, Experimento de Incêndio, Gases de Incêndio.

\footnotetext{
${ }^{1}$ Coronel do Corpo de Bombeiros Militar do Distrito Federal (Quadro Complementar). Doutor em Física e PhD em Segurança contra Incêndio pelo NIST/EUA. Email: george.braga@gmail.com.

${ }^{2}$ Tenente Coronel do Corpo de Bombeiros Militar de Pernambuco. Doutor em Engenharia Civil, com ênfase em Segurança Contra Incêndio - UFPE. Email: cristianocorreacbmpe@gmail.com.

${ }^{3}$ Capitão do Corpo de Bombeiros Militar do Distrito Federal. Mestre em Engenharia Civil - UnB. Email:

${ }^{4}$ Doutor em Egenharia Química pela UFPE. Professor do Departamento de Engenharia Química UFPE. Email jorge.cavalc@ufpe.br.

${ }^{5}$ Tenente do Corpo de Bombeiros Militar do Distrito Federal. Instrutor de Combate a Incêndio do CBMDF.
} 


\title{
FIRES IN ENVIRONMENTS WITH BRAZILIAN AND FOREIGN MATERIAL: A COMPARATIVE STUDY
}

\begin{abstract}
The actual article presents an experimental study that aims to compare the development of a fire full scale of a furnished environment with Brazilian materials, and another analog experiment with foreign furniture (England and The United States of America). Assessing the temperatures reached, the heat fluxes, the emanated gases and the thermic and conventional images. Verifying that, for environments containing a sofa and a TV each, being made in Brazil in the first experiment, and with an English sofa and an American TV in the second. It comes out from the presented data that the environment furnished with foreign materials presented a longer delay reaching the maximum values of temperature and heat flux. In general, the maximum values in the same environment were always lower on the foreign one, about both temperature and heat flux, when compared to the environment with Brazilian furniture. It came out also that both the carbon monoxide and carbon dioxide in the environment furnished with Brazilian furniture would be lethal to $50 \%$ of the population after three minutes from the beginning of the combustion process if the inmate kept standing behind the sofa (gas collection point).
\end{abstract}

Keywords: safety fire, full size essay, fire experiment, fire gases. 


\section{INTRODUÇÃO}

A realização de ensaios de incêndio em tamanho real é de grande importância para a aferição do comportamento do fogo, em especial para a melhoria da prevenção, combate e da investigação de incêndio (CORRÊA, et al., 2017). Cada vez mais se verifica um comportamento mais agressivo dos incêndios ocorridos no Brasil (PERES, 2019).

Fatores como tipo do material existente no local, tamanho do ambiente e ventilação podem impactar de forma significativa o desenvolvimento do incêndio, agravando as consequências para as pessoas e secundariamente aumentando as perdas materiais (BRAGA, NETO e SALAZAR, 2016).

No Brasil, diferente de países da Europa e da América do Norte, é pouco utilizado materiais na confecção de mobiliário e eletrodomésticos que possuam na sua constituição retardante de chamas e mesmo composição menos ígneas (neste estudo não se utilizou mobiliário com retardante). Desta forma, é importante realizar estudos para verificar o comportamento do incêndio em ambientes similares, contendo mobiliários brasileiros e de outras nações com legislações e culturas mais cuidadosas quanto a Segurança Contra Incêndio $\mathrm{SCl}$. Neste estudo foram utilizados peça de mobiliário e eletrodoméstico com dimensões e especificações muito semelhantes, de fabricação brasileira (ambiente 1) e estrangeira (ambiente 2).

Os ensaios com incêndios em tamanho real mais discutidos no mundo foram realizados fora da América Latina, com um destaque especial para os experimentos realizados pelo National Institute of Standards and Technology / NIST - EUA, com o apoio do Corpo de Bombeiros de Nova York (FDNY) e outros organismos. Um experimento com 14 eventos de incêndio real foram realizados em um prédio de 7 pavimentos, sendo ensaiados vários cenários de desenvolvimento e combate as chamas. Todos estes eventos iniciaram com um incêndio na respectiva sala mobiliada (NIST, 2009). 
Cardington, no Reino Unido, foi uma iniciativa de grande visibilidade, onde uma equipe multidisciplinar analisou $o$ incêndio natural em oito compartimentos previamente preparados, com revestimentos, carga-incêndio e condições de ventilação distintos, tendo como principal objetivo a busca do refinamento dos Eurocodes (LENNOW e MOORE, 2003).

No Brasil e na América Latina ainda são bem raros estes eventos. Apenas na última década se tem relatos de pesquisas e análises de incêndio em escala real (CORRÊA, et al., 2017; LORENZI, et al., 2013; CORRÊA, et al., 2018), mais ainda assim nenhum comparando mobiliário nacional com outros de fabricação externa ao país.

Um ramo importante do entendimento e letalidade dos incêndios reside nos gases por eles emanados. Sendo estes a maior causa de mortes nestes trágicos eventos (DAVID, et al., 2017). Visto a intoxicação exógena, proveniente da inalação de gases da combustão. Contudo pesquisas que coletem e analisem estes gases são raras, principalmente no contexto latinoamericano (CORRÊA, et al., 2017).

Por isso, foram desenvolvidos testes que pudessem comparar o desenvolvimento do incêndio em um ambiente médio compartimentado, onde não houvesse diferença em termos de geometria, material construtivo e ventilação, mas apenas do material combustível existente no local, isto é o mobiliário. Desta forma, buscou-se verificar com estes experimentos a influência da composição de mobiliários e eletrodomésticos brasileiros (primeiro experimento) e estrangeiros (segundo experimento), fabricado sob outro marco normativo em SCl.

Com a preocupação advinda dos gases emanados do incêndio foi realizada, durante o experimento, a coleta e consequente analise através de um protocolo experimental (não normatizado), visto a inexistência de norma no subcontinente (América Latina) para coleta de gases de incêndio em escala real. 


\section{METODOLOGIA}

Para verificar a diferença de comportamento do incêndio advindo da queima de materiais fabricados no Brasil e estrangeiro, foram feitos dois experimentos similares construídos através de duas salas com estrutura de aço leve (Stell Frame) e paredes e teto em drywall (gesso acartonado) com dimensões de 2,4 metros de largura, por 3,6 metros de comprimento e 2,4 metros de altura (ver Figura 1 abaixo). Neste ambiente foi colocada uma abertura com 0,8 metros de largura e 2,1 metros de altura, representando uma porta aberta em um cômodo. construídas nas instalações do Centro de Treinamento do Corpo de Bombeiros Militar do Distrito Federal - CBMDF.

Figura 1 - Ambiente construído para ensaios de Incêndio

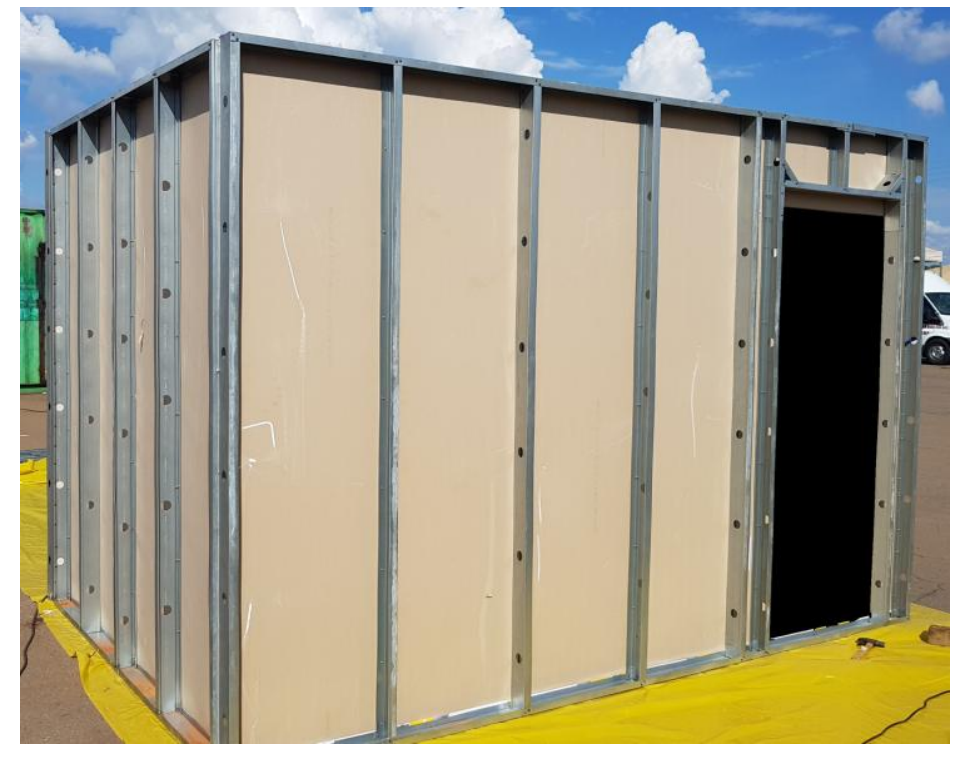

Fonte: Imagens da pesquisa

Estes ambientes foram mobiliados com televisão - TV e sofá brasileiro (ambiente 1) e TV estadunidense e sofá inglês (ambiente 2), respectivamente. Os sofás eram um pouco diferentes, pois não foi possível a aquisição de dois sofás idênticos, mas as TV's eram semelhantes (mesmo fabricante e modelo, apenas uma sendo adquirida no Brasil e outro nos Estados Unidos da América 
- EUA). Os sofás podem ser vistos na Figura 2 abaixo e uma foto da TV, pois elas são visualmente idênticas, na Figura 3.

Figura 2 - Foto dos sofás brasileiro (a) e inglês (b).

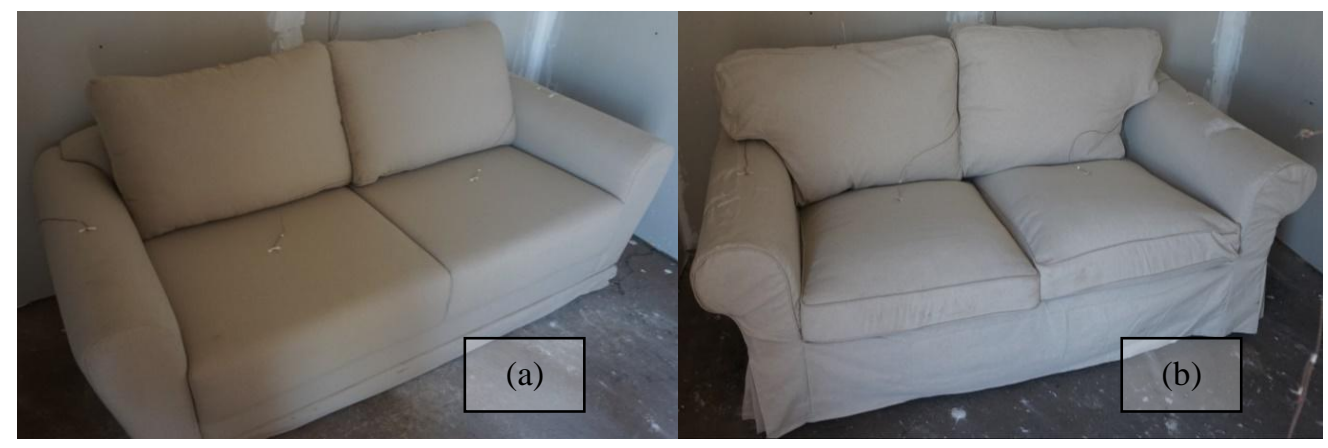

Fonte: Imagens da pesquisa

O sofá foi colocado no fundo do ambiente, longe da porta, e a televisão foi colocada na parede contrária ao sofá, próximo à porta. A disposição do mobiliário e da TV podem ser vistas na figura abaixo.

Figura 3 - Foto da posição do sofá (a), da TV (b) e visão externa da TV no ambiente.

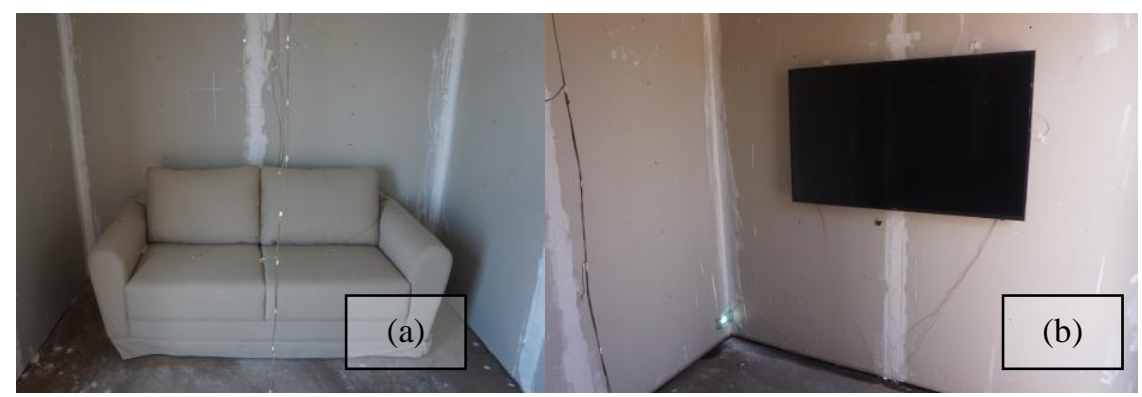

Fonte: Imagens da pesquisa

Todo o teste foi acompanhado por meio de câmeras de alta-definição (seta amarela), uma para acompanhar o sofá e outra para a TV, e por meio de uma câmera térmica (seta vermelha) apontada também para o sofá (Ver Fig.4). 
Figura 4 - Posicionamento das câmeras de alta-definição (seta amarela) e térmica (seta vermelha).

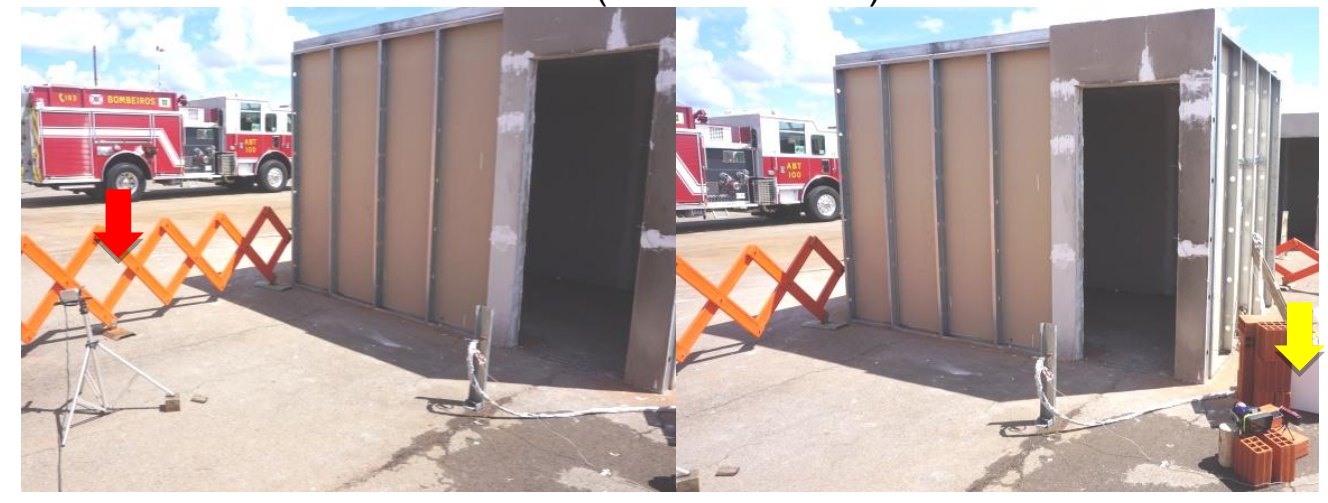

Fonte: Imagens da pesquisa

Para melhor avaliar o comportamento do fogo foram utilizados termopares do tipo $\mathrm{k}$ e sensores de fluxo de calor do tipo Schmidt-Boelter. No total foram colocados 9 sensores termopares no centro do ambiente, 6 no sofá, 3 na TV, 3 na porta e mais 6 para monitorar a temperatura nas paredes de gesso acartonado (ver Figura 2 e Figura 3 acima). Além disso, foi colocado um sensor de fluxo de calor apontado para o sofá dentro do ambiente e mais outro do lado de fora, apontado para a abertura que representava a porta (setas verdes na Figura 5). Os medidores estavam conectados a um sistema de arrefecimento, para garantir que a temperatura interna do medidor estava na sua faixa de calibração (caixa branca na figura abaixo).

Durante todo o experimento os termopares aferiram as temperaturas, destacando que a incerteza nestas medições é da ordem de $2,2^{\circ} \mathrm{C}$ abaixo de $293{ }^{\circ} \mathrm{C}$ e $+/-0,75 \%$ acima disso (OMEGA ENGINEERING, 2004). Para o caso do fluxo de calor, a incerteza do componente de calibração para os dispositivos do tipo Schmidt-Boelter é, de acordo com o fabricante, da ordem de $\pm 3 \%$ (MEDTHERM, 2003). Resultados de um estudo sobre a resposta e calibração em medidores de fluxo de calor demonstram que a incerteza expandida para medidores do tipo Schmidt-Boelter gauge é da ordem de $\pm 8 \%$ (PITTE, et al., 2006). 


\section{Revista FLAMMAE}

Revista Científica do Corpo de Bombeiros Militar de Pernambuco

Artigo Publicado no Vol.07 N.20 - Edição Especial 2021 - ISSN 2359-4829

Versão on-line disponível em: http://www.revistaflammae.com

Figura 5 - Localização dos sensores de fluxo de calor.

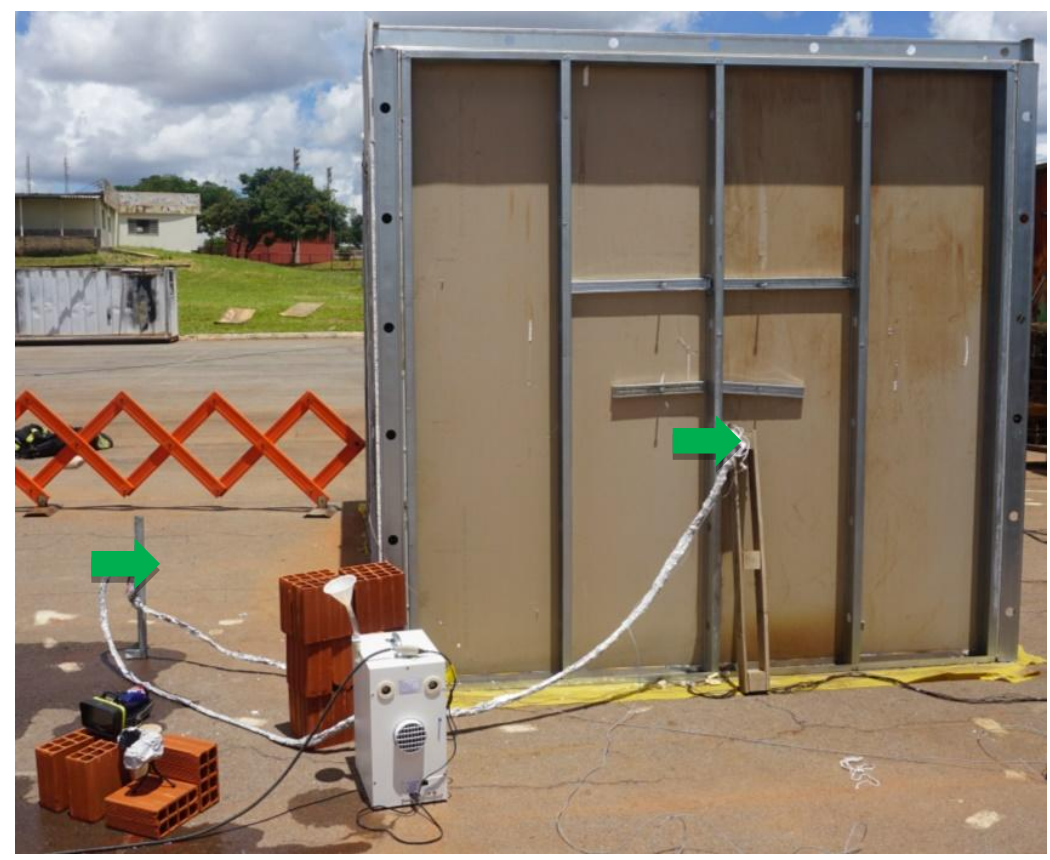

Fonte: Imagens da pesquisa

A figura abaixo representa à disposição geral do ambiente e do mobiliário e TV. Mostrando um esboço dos dispositivos (pontos brancos para os termopares e amarelo para os medidores de fluxo de calor).

Figura 6 - Esboço do local de ensaio e sua instrumentação.

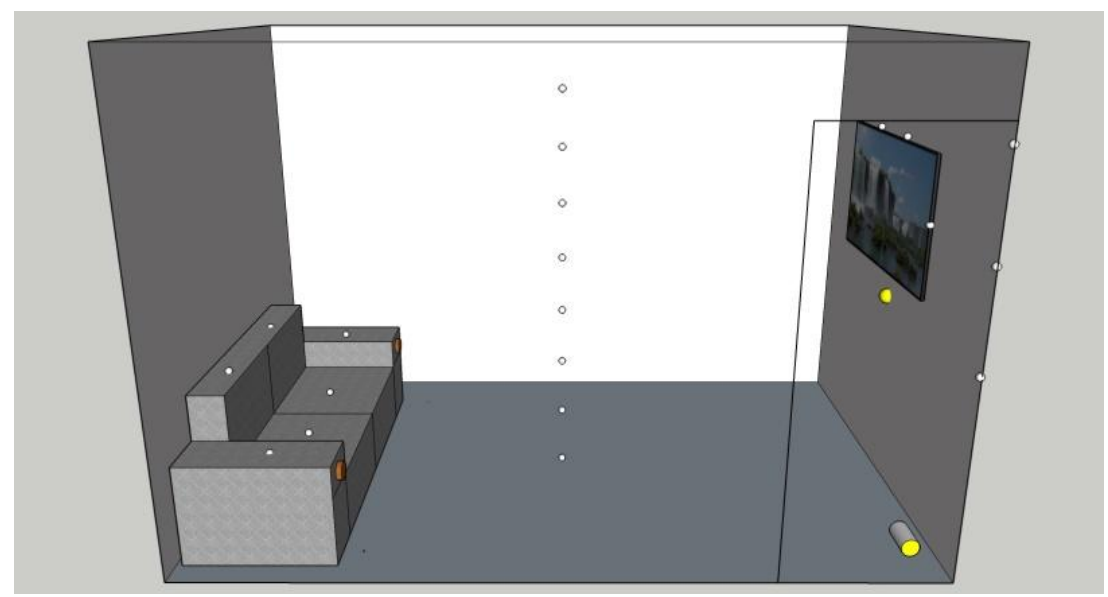

Fonte: Imagens da pesquisa 


\section{Revista FLAMMAE}

Revista Científica do Corpo de Bombeiros Militar de Pernambuco

Artigo Publicado no Vol.07 N.20 - Edição Especial 2021 - ISSN 2359-4829

Versão on-line disponível em: $\underline{\text { http://www.revistaflammae.com }}$

Todos os dados foram coletados em um chassi CompactDAQ com módulos de medição de temperatura e voltagem da National Instruments e armazenados em um computador por meio de um programa desenvolvido especialmente para o experimento em LabView.

Figura 7 - Sistema de aquisição de dados.

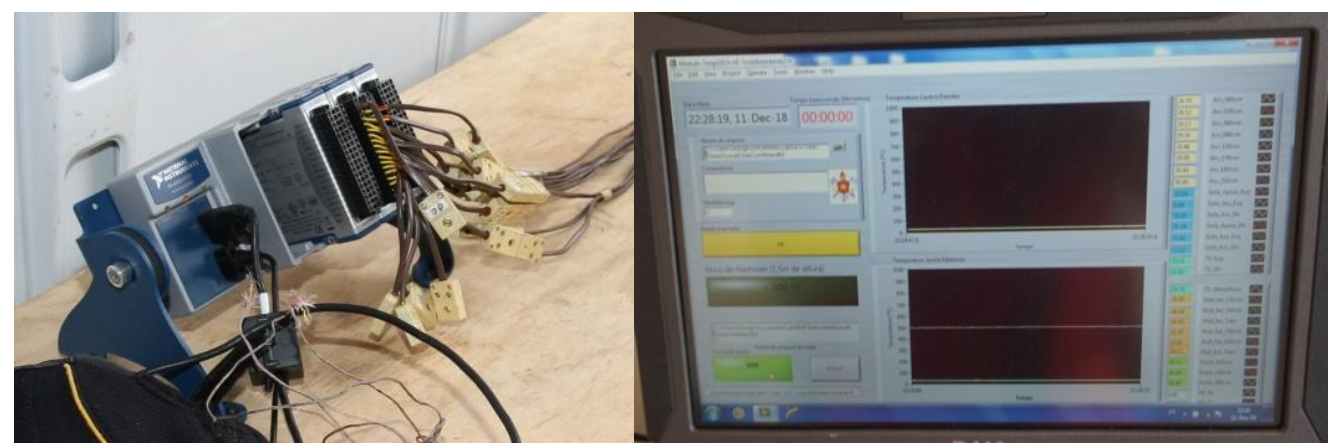

Fonte: Imagens da pesquisa

A vela era acesa e depositada no lado esquerdo do sofá, na junção entre o assento e o apoio de braço lateral e com o pavio voltado para o encosto (Ver seta na Figura 8), sendo que o desenvolvimento do incêndio era acompanhado até que o sofá entrasse em combustão. A vela sempre foi colocada da mesma forma, não tendo sido movimentada após a sua colocação.

Figura 8 - Posição de colocação da fonte de ignição (vela) no sofá.

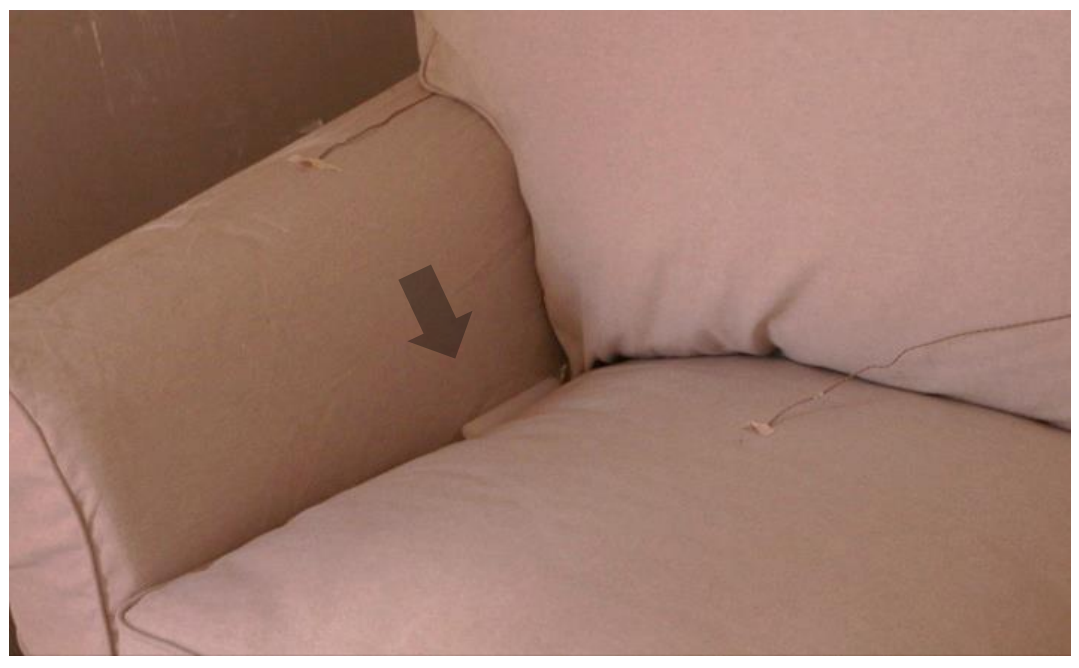

Fonte: Imagens da pesquisa 
Revista Científica do Corpo de Bombeiros Militar de Pernambuco

Artigo Publicado no Vol.07 N.20 - Edição Especial 2021 - ISSN 2359-4829

Versão on-line disponível em: http://www.revistaflammae.com

Para a coleta dos gases foram utilizados ampolas em vidro cilindricas, com duas torneiras nas extremidades e capacidade de $125 \mathrm{ml}$.

Aplicou-se um semi-vácuo com uma seringa de $10 \mathrm{ml}$, que foi aspirada por dez vezes em sequencia em cada ampola, buscando uma pressão negativa padrão em todas as coletas. Estas ampolas foram etiquetadas e acondicionadas em bancada própria, sendo utilizadas respectivamente para aspirar os gasese nos dois experimentos, como se vê a seguir na figura 9. Para a coleta as ampolas eram posicionadas em um pequeno orifício na parede próxima ao sofá, na altura de $1,6 \mathrm{~m}$, aproximadamente onde localiza-se a boca e nariz (aspiração) de homem de estatura mediana conforme parâmetros brasileiros (FIGUEIROA, 2012).

Figura 9 - Ampolas sendo preparadas e dispostas na bancada
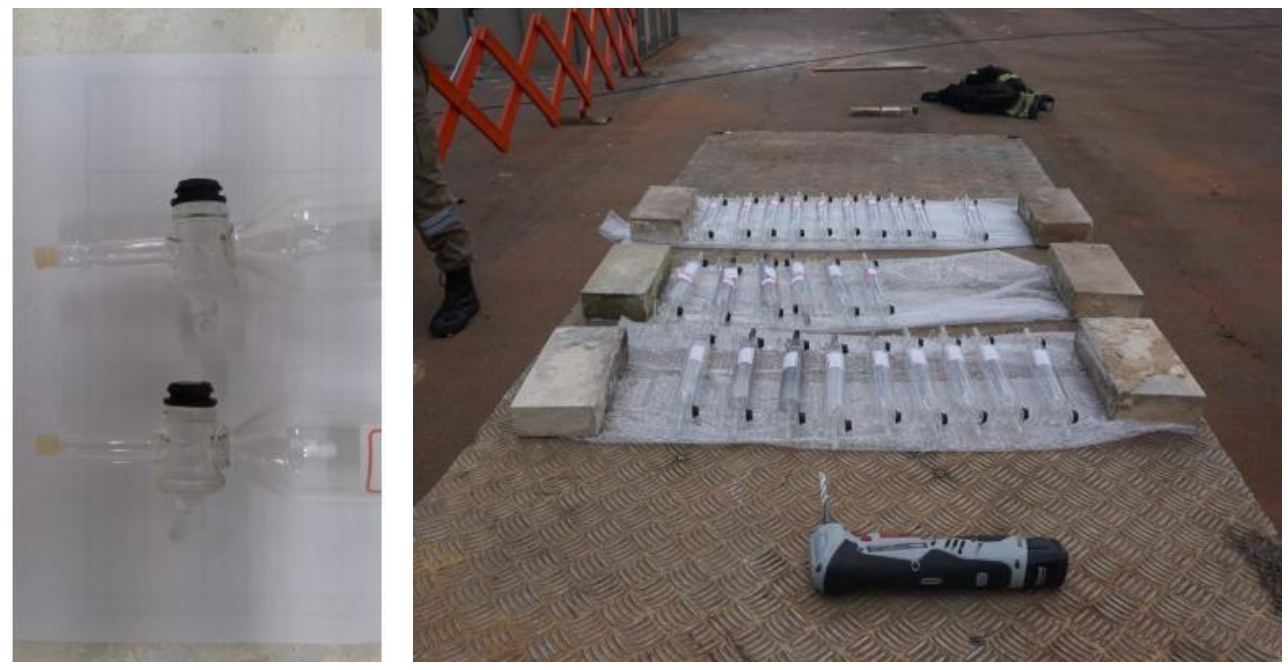

Fonte: Imagens da pesquisa

\section{RESULTADOS}

As duas queimas foram realizadas no mesmo dia, com diferença de 30 minutos entre elas. As condições climáticas eram favoráveis (ver Figura 10), 
sendo um dia sem chuva, com temperatura média da ordem de $23{ }^{\circ} \mathrm{C}$ e umidade relativa do ar na faixa de $80 \%$ (fonte INMET).

Figura 10 - Condições do ambiente durante a queima.

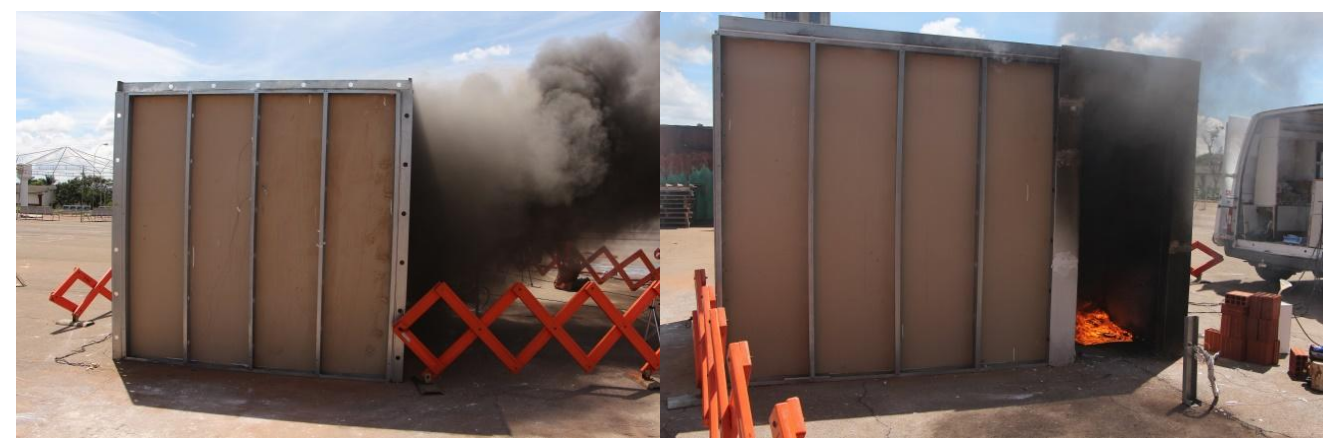

Fonte: Imagens da pesquisa

Abaixo estão apresentados alguns resultados obtidos, em especial as temperaturas observadas no ambiente, por meio dos termopares colocados no centro deste, da temperatura nos objetos (sofá e TV) e do fluxo de calor observado dentro do ambiente e a um metro de distância da porta.

\subsection{Medição de temperatura}

Nos gráficos abaixo são apresentadas as temperaturas para diferentes alturas nos ambientes com mobiliário brasileiro (Figura 11) e estrangeiro (Figura 12). Por esses gráficos é possível verificar que no ambiente com mobiliário brasileiro as temperaturas na camada gasosa atingiram valores maiores, além de terem um desenvolvimento mais rápido. 
Figura 11 - Gráfico da temperatura em diferentes alturas no centro do ambiente com mobiliário do Brasil.

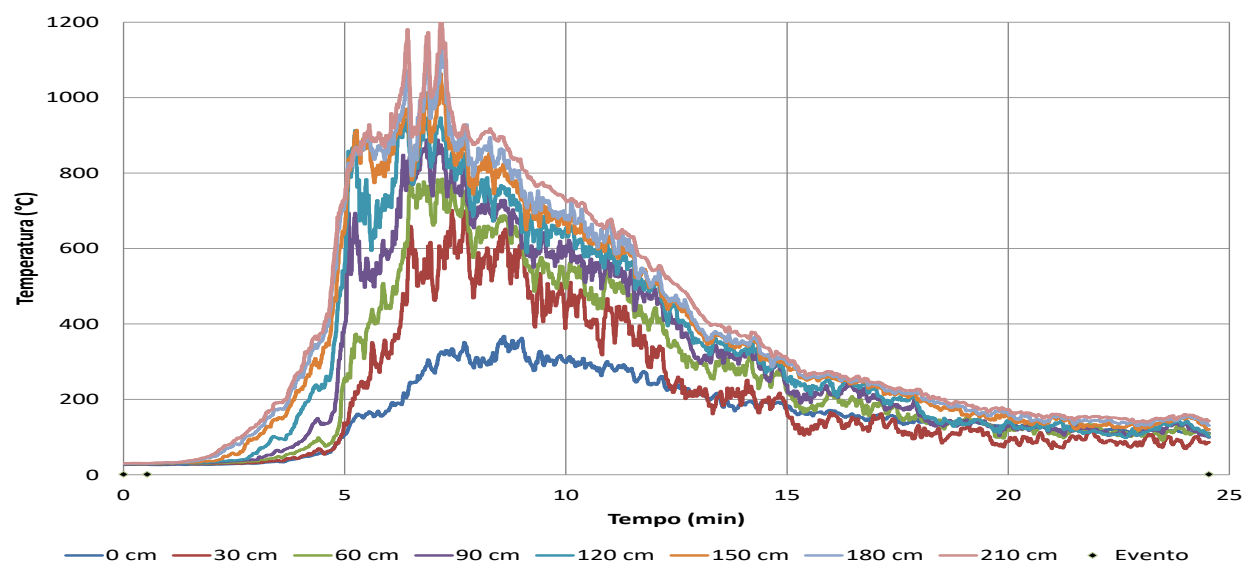

Fonte: Dados da pesquisa

Figura 12 - Gráfico da temperatura em diferentes alturas no centro do ambiente com mobiliário do estrangeiro.

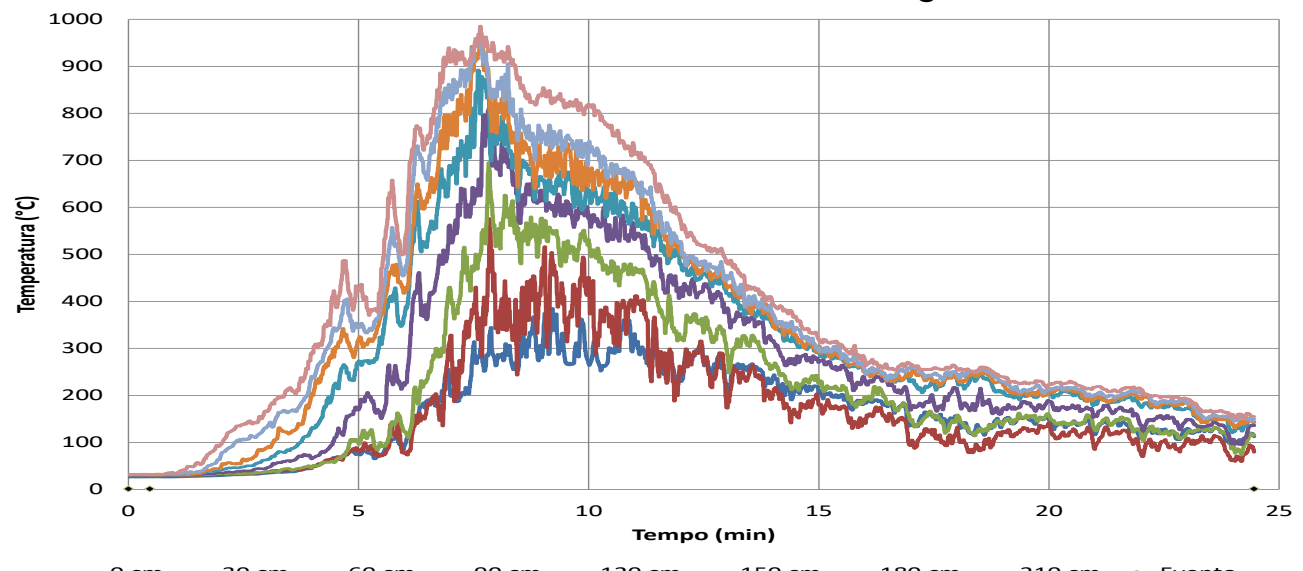

Fonte: Dados da pesquisa

A diferença da velocidade de desenvolvimento da temperatura do incêndio pode ser melhor visto quando comparamos algumas curvas $(30,120 \mathrm{e}$ $210 \mathrm{~cm}$ de altura) no mesmo gráfico (Figura 13). Nele é possível verificar a diferença de velocidade e aumento da temperatura entre os experimentos com mobília estrangeira (linha sólida) e mobília do Brasil (linha pontilhada). Além disso, é possível verificar que o ambiente com mobília brasileira, após um início 
Revista Científica do Corpo de Bombeiros Militar de Pernambuco

Artigo Publicado no Vol.07 N.20 - Edição Especial 2021 - ISSN 2359-4829

Versão on-line disponível em: http://www.revistaflammae.com

mais acelerado e com temperaturas mais elevadas, tem um decaimento de temperatura com tempo próximo do ambiente com mobiliário dos EUA (ver tempo acima de 10 minutos), indicando que ele, além de evoluir mais rapidamente, permanece com temperaturas elevadas por mais tempo.

Figura 13 - Gráfico comparativo de temperatura no centro do ambiente com mobiliário Estrangeiro (linha sólida) e do Brasil (linha pontilhada).

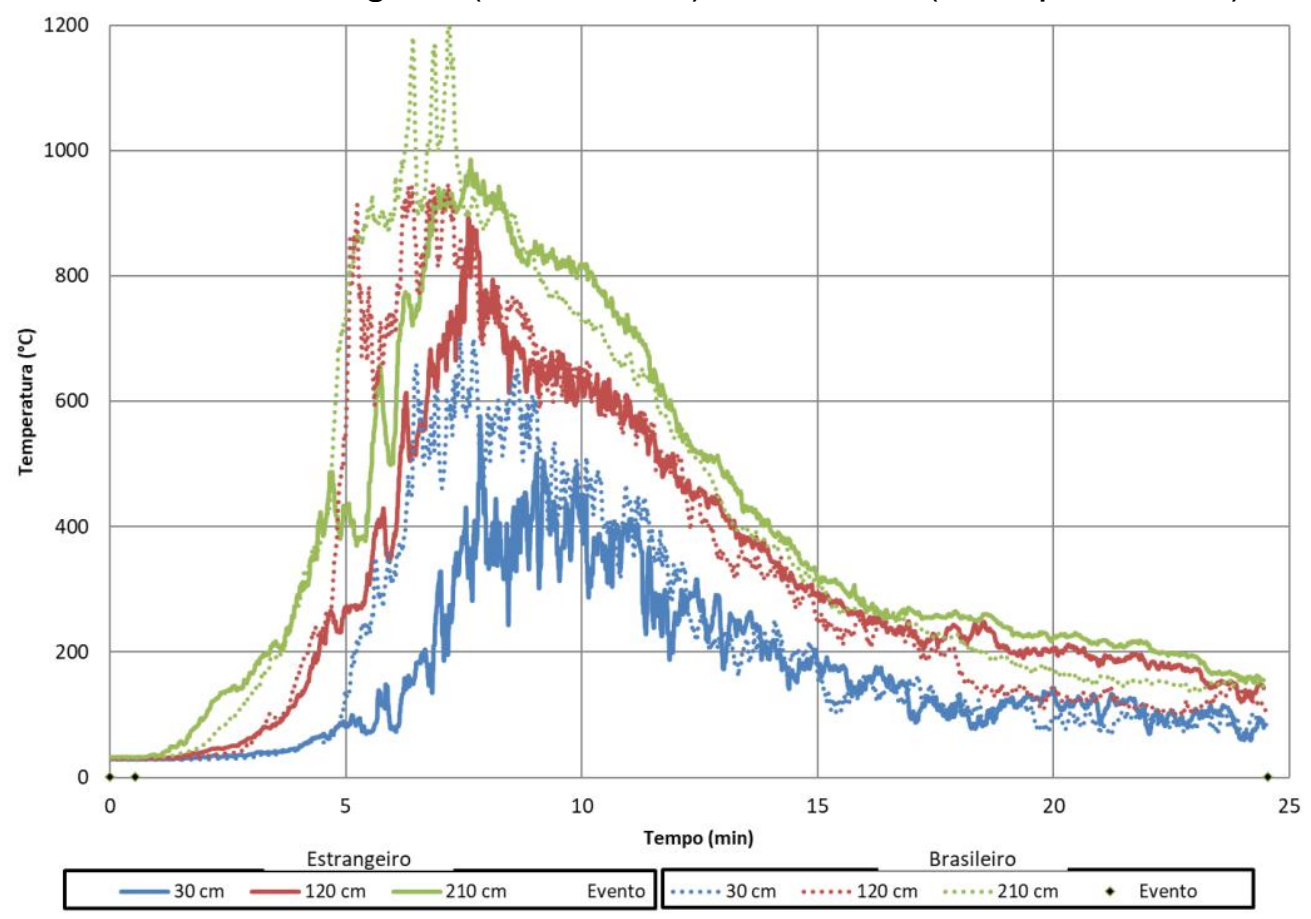

Fonte: Dados da pesquisa

Além disso, foi possível medir a temperatura nos sofás e TVs. No caso dos sofás é possível verificar que o brasileiro (Fig. 14) tem um aumento de temperatura muito próximo em todas as suas partes, mostrando que rapidamente a peça como um todo contribui para a grandeza do incêndio. No caso do sofá estrangeiro (inglês), houve uma evolução de temperatura de forma mais gradativa, apresentando uma diferença na evolução da temperatura entre os lados esquerdo e direito do sofá. 
Revista Científica do Corpo de Bombeiros Militar de Pernambuco

Artigo Publicado no Vol.07 N.20 - Edição Especial 2021 - ISSN 2359-4829

Versão on-line disponível em: $\underline{\text { http://www.revistaflammae.com }}$

Figura 14 - Evolução da temperatura no sofá brasileiro.

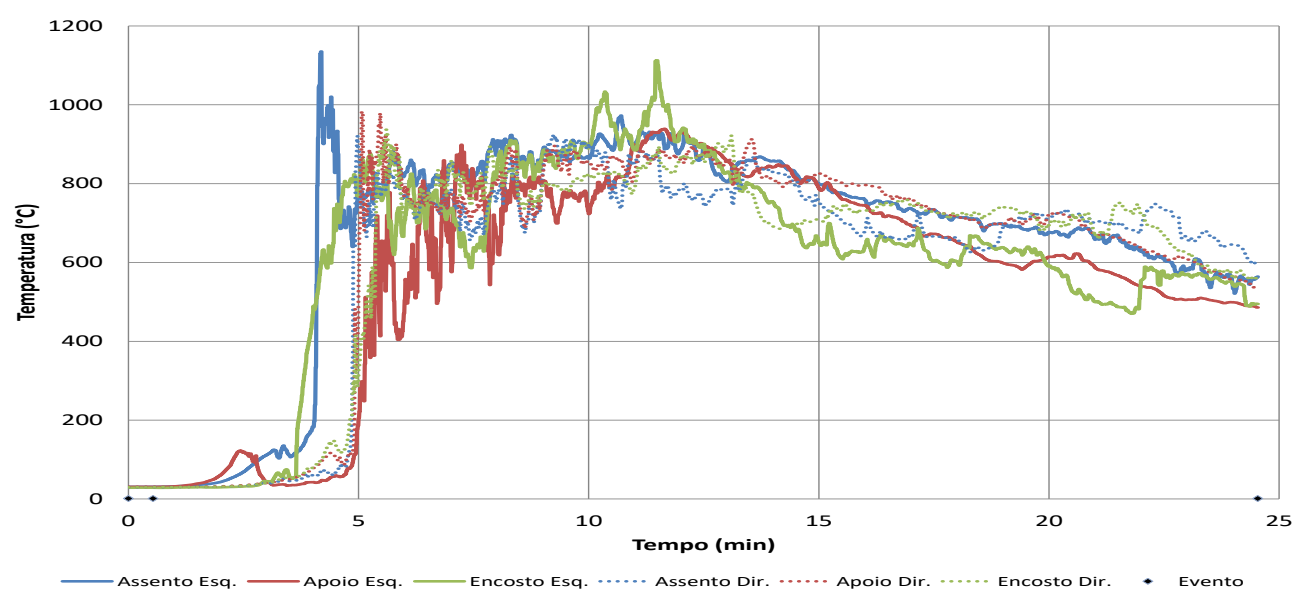

Fonte: Dados da pesquisa

Figura 15 - Evolução da temperatura no sofá estrangeiro(inglês).

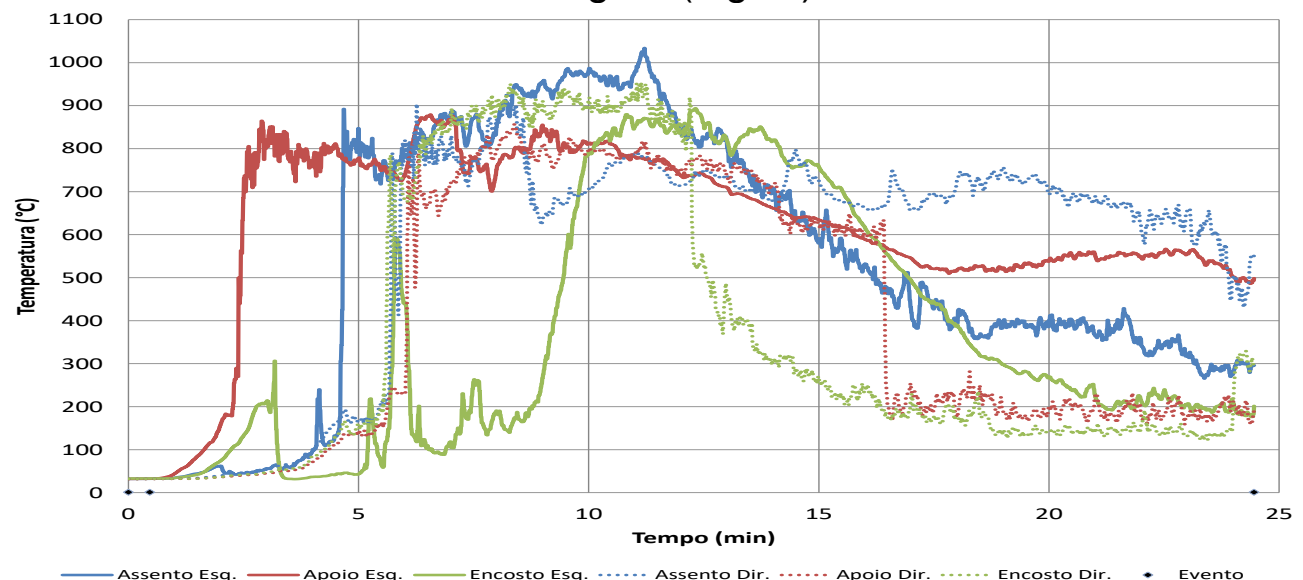

Fonte: Dados da pesquisa

No caso das TVs brasileira e estrangeira (EUA) o comportamento foi semelhante, contudo pode ser visto uma pequena diferença em favor da TV estrangeira. No gráfico abaixo é possível ver a comparação de temperatura nos pontos superiores das TVs. 
Revista Científica do Corpo de Bombeiros Militar de Pernambuco

Artigo Publicado no Vol.07 N.20 - Edição Especial 2021 - ISSN 2359-4829

Versão on-line disponível em: $\underline{\text { http://www.revistaflammae.com }}$

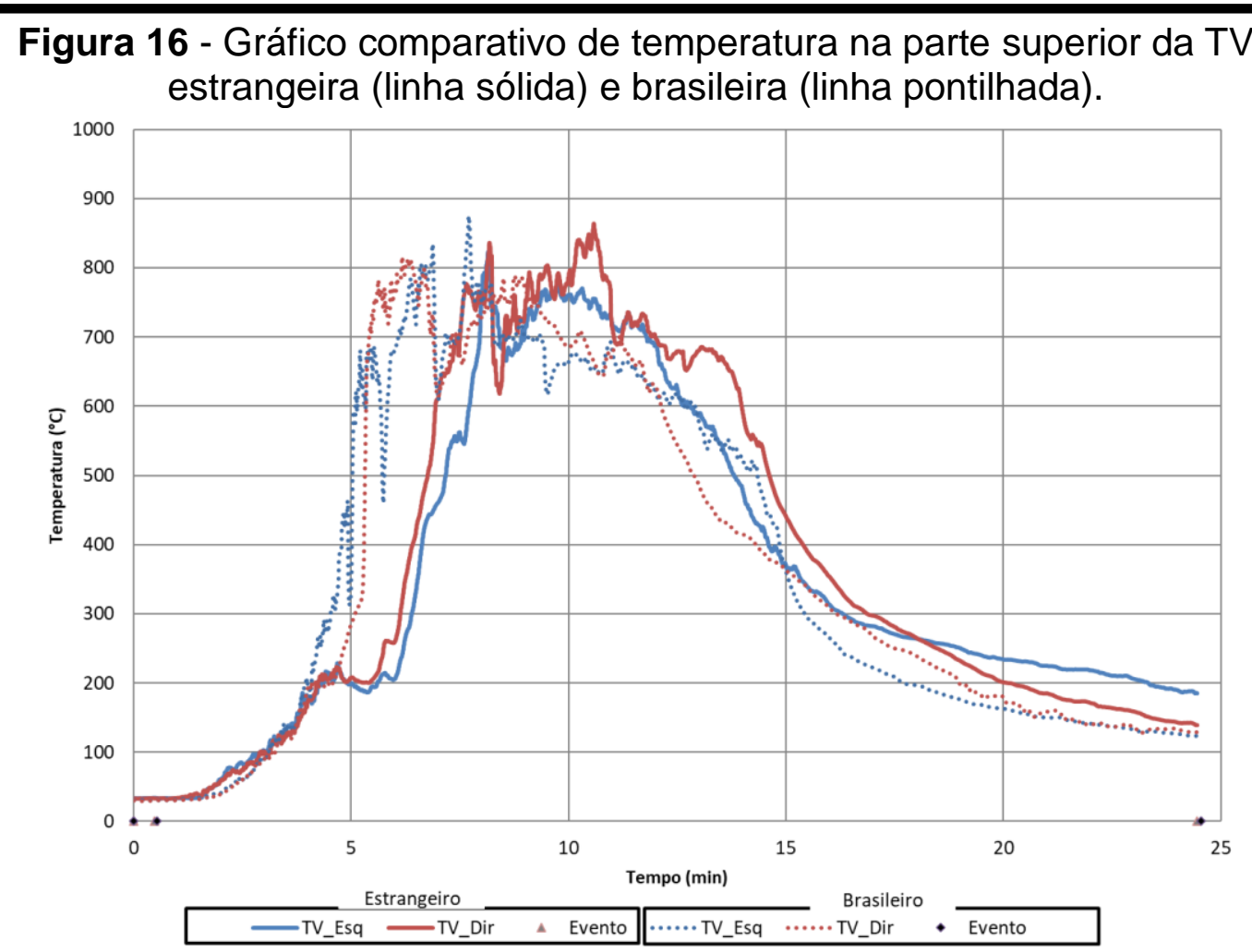

Fonte: Dados da pesquisa

4.2. Medição do fluxo de calor

Mais importante que verificar o comportamento das temperaturas em um incêndio é medir o fluxo de calor liberado por ele, pois representa uma medida direta da grandeza deste.

No gráfico abaixo (Figura 17) é possível verificar que houve uma grande diferença entre os dois tipos de mobiliário. No caso do ambiente que possuía mobiliário brasileiro, o fluxo de calor chegou a atingir picos de $100 \mathrm{~kW} / \mathrm{m}^{2}$ na parte interna e, quando avaliado pelo medidor colocado do lado de fora, atingiu picos da ordem de $18 \mathrm{~kW} / \mathrm{m}^{2}$. Para o ambiente com mobiliário estrangeiro, o sensor interno apresentou picos da ordem de $80 \mathrm{~kW} / \mathrm{m}^{2}$ no interior, enquanto, do lado de fora, apresentou picos de $7,7 \mathrm{~kW} / \mathrm{m}^{2}$. Além disso, é possível verificar que houve um crescimento mais rápido do fluxo de calor em tempos muito mais curtos no ambiente com mobiliário brasileiro. 
Figura 17 - Gráfico do fluxo de calor interno e externo (1 metro da porta) para os dois ambientes ensaiados (linha contínua estadunidense e linha pontilhada brasileiro).

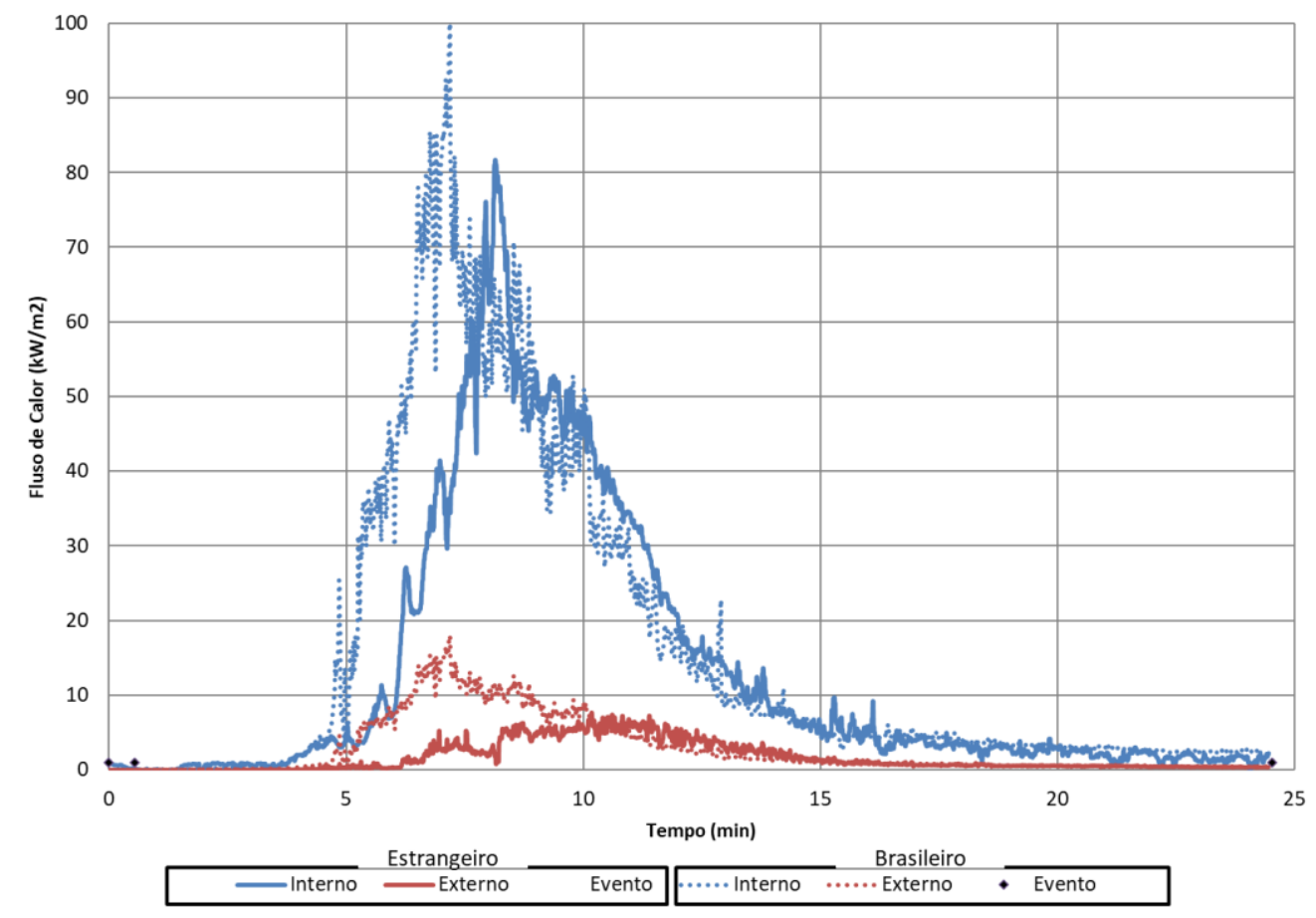

Fonte: Dados da pesquisa

\subsection{Imagens térmicas}

Por meio das imagens da câmera térmica, pode-se ver que existe uma diferença no visual da propagação do fogo nos sofás brasileiro (Figura 17) e estadunidense (Figura 18), estando consistente com o verificado pelos sensores de temperatura e fluxo de calor. 


\section{Revista FLAMMAE}

Revista Científica do Corpo de Bombeiros Militar de Pernambuco

Artigo Publicado no Vol.07 N.20 - Edição Especial 2021 - ISSN 2359-4829

Versão on-line disponível em: $\underline{\text { http://www.revistaflammae.com }}$

Figura 17 - Imagem da câmera térmica do sofá brasileiro.

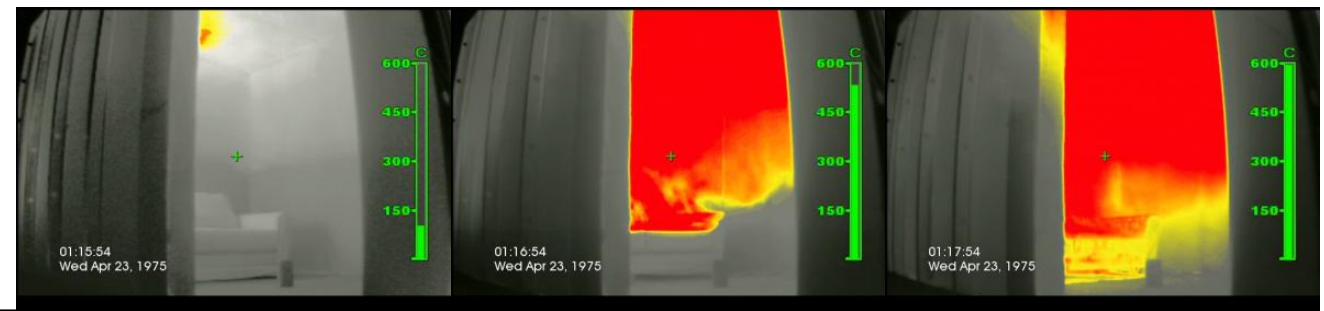

Tempo abrox. de 4

Tempo abrox. de 5

Tempo abrox. de 6

Figura 18 - Imagem da câmera térmica do sofá estrangeiro.

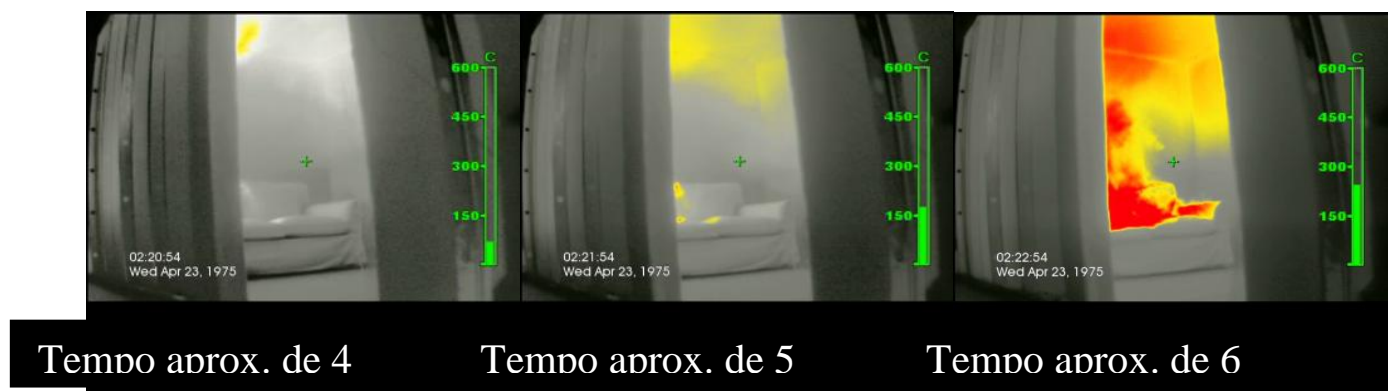

Fonte: Dados da pesquisa

Após cada coleta de gases o pequeno orifício usado para encaixe da ampola era vedado com tampão de material aluminizado, como pode ser visto na Figura 19.

Figura 19 - Preparação e Coleta de Gases
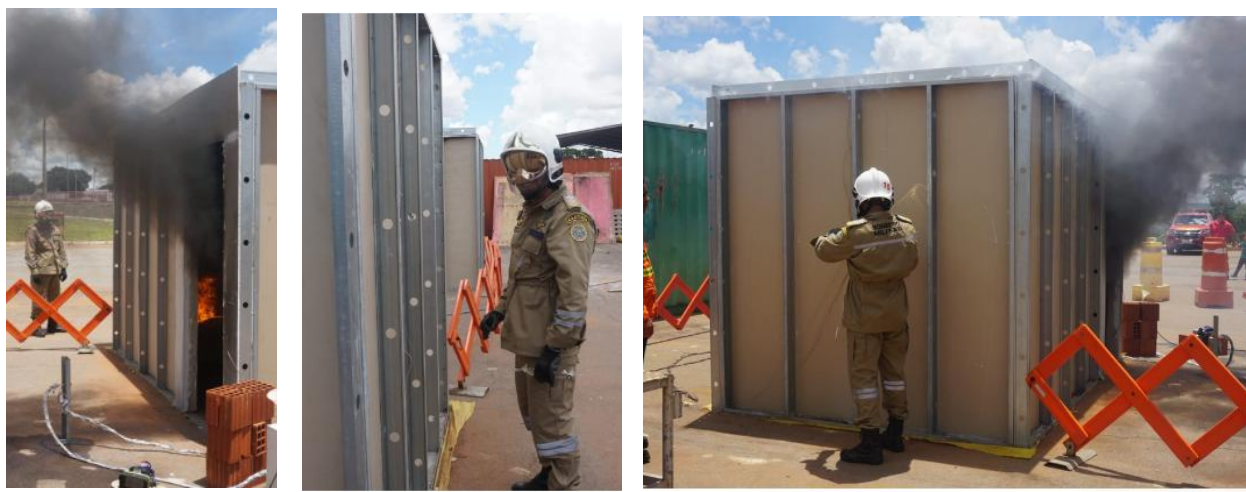

Fonte: Imagens da pesquisa 
O processo de análise das amostras foi realizado em laboratório da Universidade Federal de Pernambuco, através da cromatografia gasosa.

Nesta análise, foi utilizada Injeção de 200 microlitros em modo splitless, com temperatura $40^{\circ} \mathrm{C}$ durante 2,5 minutos, com aquecimento $20^{\circ} \mathrm{C} / \mathrm{min}$ até $80^{\circ} \mathrm{C}$, mantidos por mais $5 \mathrm{~min}$. Coluna Porapak- $\mathrm{N}$, Nitrogênio como gás de arraste, com vazão $30 \mathrm{~mL} / \mathrm{min}$. E realizado em Cromatógrafo HP $5890 \mathrm{com}$ detector de condutividade térmica, recentemente calibrado e inspecionado.

Os primeiros resultados quanto as taxas de $\mathrm{CO}$ (Monóxido de carbono) e CO2 (Dióxido de carbono) estão expressos na tabela a seguir:

Tabela 1 - Resultados de Gases de Incêndio em Escala Real.

\begin{tabular}{ccc}
\hline $\begin{array}{c}\text { Tempos } \\
\text { (minutos) }\end{array}$ & $\begin{array}{c}\text { Monóxido de } \\
\text { Carbono (\%) }\end{array}$ & $\begin{array}{c}\text { Dióxido de } \\
\text { Carbono (\%) }\end{array}$ \\
\hline 3 & 1,60 & 5,87 \\
5 & 1,67 & 5,22 \\
7 & 1,65 & 5,33 \\
11 & 1,70 & 5,36 \\
13 & 1,71 & 5,75 \\
& & \\
\hline
\end{tabular}

Fonte: Dados da pesquisa

Destaca-se que os dados preliminares dizem respeito a sala que continha mobiliário brasileiro, visto que nos EUA e Inglaterra já existe um bom conhecimento da toxicidade dos móveis e eletrodomésticos lá fabricados.

\section{CONCLUSÕES}

O incêndio foi iniciado com uma vela colocada na posição horizontal no canto esquerdo de cada um dos sofás. Após acessa a chama, foi iniciada a 
coleta de dados. Sendo marcado como ponto inicial o momento em que 0 material do sofá começou a pegar fogo, bem como o ponto final do experimento o término da queima dos materiais combustíveis presentes no compartimento.

Foi possível verificar, em boa parte dos dados aferidos, que o ambiente constituído de materiais estrangeiros apresentou um demora maior para atingir valores máximos de temperatura e fluxo de calor. Além disso, em geral, os valores máximos neste ambiente sempre foram menores, tanto de temperatura quanto de fluxo de calor, quando comparado ao ambiente com mobiliário brasileiro.

Além disso, as imagens térmicas e de alta resolução aferiram uma visível diferença de comportamento de queima desses ambientes, em especial quanto a produção de chamas e mesmo de fumaça, como também no tempo de queima da TV.

O monóxido de carbono tem uma alta afinidade com a hemoglobina, tornando-se um competidor (com muito mais atração química) do oxigênio (DAVID, et al., 2017). Assim rapidamente através do sangue o monóxido se espalha por todos os órgãos e tecidos do corpo humano (INACIO e BRANDÃO, 2016). Mas o principal malefício desta intoxicação é a anoxia resultante da conversão de oxihemoglobina em carboxihemoglobina $(\mathrm{COHb})$, visto que a afinidade do monóxido de carbono é de cerca de 200 a 250 vezes maior a hemoglobina que o oxigênio (LACERDA, LEROUX e MORATA, 2005).

A exposição ao monóxido de carbono, por certo período de tempo, à concentração de $10 \mathrm{ppm}$ produzirá sinais de envenenamento enquanto que com 100 ppm é letal para $50 \%$ da população submetida a tal ambiente por alguns minutos (JACHID e JACHID, 2001).

O dióxido de carbono ou gás carbônico é encontrado no ar atmosférico em percentuais médios de 0,03\% (JACHID e JACHID, 2001), no experimento em tela esta taxa foi 191 vezes maior. 
Quanto a coleta de gases verificou-se que a altura de $1,6 \mathrm{~m}$ as taxas de monóxido de carbono e dióxido de carbono poderiam ser letais para um ocupante na posição de pé no ambiente incendiado, a partir do terceiro minuto após o início da combustão, revelando a possibilidade do uso do protocolo experimental, como mais um parâmetro de aferições feitas em experimentos de incêndio em escala real.

\section{AGRADECIMENTOS}

Os autores agradecem ao apoio da Financiadora de Estudos e Projetos - FINEP, por meio dos equipamentos de medição adquiridos pelo projeto Melhoria dos Procedimentos de Combate e Investigação de Incêndio-MODFOGO, e da ABICHAMA, pelo apoio em adquirir o material que foi utilizado no experimento. Além disso, os autores também agradecem o apoio do Centro de Treinamento Operacional, Grupamento de Prevenção e Combate a Incêndio Urbano e da Diretoria de Investigação de Incêndio do Corpo de Bombeiros Militar do Distrito Federal, Universidade Federal de Pernambuco e da equipe que apoiou diretamente na execução do experimento, em especial aos bombeirosmilitares: Luciano Maximiano da Rosa, Valmeci Domingo dos Santos, Marcelo dos Santos Cirilo, Cláudio José Leme, Ismael Moura de Souza e Bruno Marcelino de Almeida Nunes.

\section{REFERÊNCIAS}

BRAGA, G. C.; NETO, J. P. L. e SALAZAR, H. D. F. A temperatura e fluxo de calor em uma situação de incêndio e as consequências para os bombeiros. Revista FLAMMAE, Recife, 2(4), 09-28, 2016. 
CORRÊA, C.; BRAGA, G. C.; BEZERRA JUNIOR; J. C., RÊGO SILVA, J. J., TABACZENSKI, R., e PIRES, T. A. Fire in residence in the City of Recife: An experimental study. Revista ALCONPAT, 7(3), 215-230. 2017

CORRÊA, C., BRAGA, G. C., DE MENEZES, R. R. F., RÊGO SILVA, J. J. R., TABACZENSKI, R., BEZERRA JUNIOR, J. C., e PIRES, T. A. Natural fire tests in a dormitory with fire protected furniture. Fire Research. 2(1), 07-11, 2018.

DAVID, S., KNIELING, A., SCRIPCARU, C., DIAC, M., SANDU, I., e BULGARU ILIESCU, D. Study of Carbon Monoxide Intoxication in Fire Victimis. Rev. Chim.(Bucharest), 68, 2932-2935, 2017.

FIGUEIROA, J. N. et al. Evolução intergeracional da estatura no Estado de Pernambuco, Brasil, entre 1945 e 2006: 2-aspectos analíticos. Cadernos de Saúde Pública, v. 28, 1468-1476, 2012.

INÁCIO, D. A. D. S. e BRANDÃO, B. A. Forensic Toxicology: Carbon Monoxide Poisoning in Carbonized / Toxicologia Forense: Intoxicação por Monóxido de Carbono em Carbonizados. Brazilian Journal of Forensic Sciences, Medical Law and Bioethics, 5(3), 314-327, 2016.

JACHIC, J., e JACHIC, J. Poluiçao Monóxido de Carbono em Ambiente Fechado. Revista Tuiuti Ciência e Cultura, 25(3), 19-41, 2001.

LACERDA, A.; LEROUX, T. e MORATA, T. Efeitos ototóxicos da exposição ao monóxido de carbono: uma revisão. Pró-Fono Revista de atualização científica, 17(3), 403-12, 2005.

LENNON T. e MOORE D. The natural fire safety concept--full-scale tests at Cardington. Fire Safety Journal, 38(7), 623-643, 2003. 
LORENZI, L.S.; KLEIN, D.L.; CAETANO, L.F.; SILVA FILHO, L.C.P. e RODRIGUES, E.E.C. Avaliação do Comportamento de Edificação Habitacional construída em chapas de aço com preenchimento de poliuretano em situação de incêndio. In: $2^{\circ}$ Congresso lbero Latino Americano sobre Segurança Contra Incêndio, 2013.

MEDTHERM CORPORATION. Bulletin 118, 64 Series Heat Flux Transducers, Medtherm Corporation, Huntsville, AL., 2003.

NIST, NATIONAL INSTITUTE STANDART TECHNOLOGY. KERBER, S. e MADRYKOWSKI, D.(Org.) Fire fighting tactics under wind driven fire conditions: 7-story building experiments. NIST technical note, v. 1629, 2009.

OMEGA ENGINEERING INC. The Temperature Handbook, Vol. MM, pp Z-3940, Stamford, CT, 2004.

PERES, Sarah, Incêndio atinge apartamento na 110 Norte: bombeiros resgatam duas mulheres. Disponível em <https://www.correiobraziliense.com.br/app/noticia/cidades/2018/05/14/interna_ cidadesdf,680580/incendio-atinge-apartamento-na-asa-norte-e-mobilizabombeiros.shtml >. Acesso em: 01mar. 2019.

PITTS, W. M.; ANNAGERI, V. M.; RIS J. L.; FILTZ J.-R.; NYGARD K., SMITH D. e WETTERLUND I. Round robin study of total flux gauge calibration at fire laboratories, Fire Safety Journal 41, pp 459-475, 2006. 
POPOVIC, V. M.; ATANASIJEVIC, T. C.; NIKOLIC, S. D. e MICIC, J. R.

Concentration of carbon-monoxide in carbonized bodies-Forensic aspects. Legal Medicine, 11, S318-S320, 2009. 